\title{
Plasma cross linked fibrin degradation products in pulmonary embolism
}

\author{
Beverley J Rowbotham, Julian Egerton-Vernon, Alan N Whitaker, Mervyn J Elms, \\ Ian $\mathrm{H}$ Bunce
}

Department of Medicine A N Whitaker Royal Brisbane Hospital

Department of Pathology M J Elms

I H Bunce

Department of Nuclear Medicine $\mathrm{J}$ Egerton-Vernon

Brisbane, Australia

Address for reprint requests: Dr B J Rowbotham,

Hematology Research, Mayo Clinic, 200 SW First Street, Rochester, Minnesota 55905 USA.

Accepted 6 June 1990

A simple, non-invasive blood test for the diagnosis of pulmonary embolism has long been sought. Measurement of markers of thromboglobulin, ${ }^{1-3}$ and of fibrinolysis, such as fibrin[ogen] degradation products, ${ }^{4-6}$ was considered but abandoned because of a lack of sensitivity and specificity. With monoclonal antibody technology, a new generation of assays for fibrin degradation products is now available. ${ }^{7}$ Several of these assays react with epitopes related to the cross linking between $\gamma$ chains introduced by factor XIIIa during stabilisation of the fibrin clot. They identify the derivatives of cross linked fibrin

\begin{abstract}
University of Queensland Department of Pathology B J Rowbotham

Abstract

Plasma concentrations of cross linked fibrin degradation products, a marker of intravascular thrombosis and fibrinolysis, were measured in 495 patients with suspected pulmonary embolism referred for ventilation-perfusion lung scanning to determine whether concentrations are increased in pulmonary embolism and their potential use in diagnosis. Lung scans were described as normal $(n=66)$ or as showing a low $(n=292)$, indeterminate $(n=58)$, or high probability $(n=$ 79) of pulmonary embolism. There was a difference between the mean levels of cross linked fibrin degradation products in each scan category: normal scans, 142 $\mathrm{ng} / \mathrm{ml}$; low probability scans, $295 \mathrm{ng} / \mathrm{ml}$; indeterminate probability scans, $510 \mathrm{ng} /$ $\mathrm{ml}$; high probability scans, $952 \mathrm{ng} / \mathrm{ml}$ (p $<0.001$ ). Of the patients with high probability scans, $96 \%$ had raised concentrations. Explanations for discrepant low results include incorrect scan diagnosis, delay in blood sampling, and anticoagulation. Of the patients with a low or indeterminate probability of pulmonary embolism, $43 \%$ had increased concentrations of cross linked fibrin degradation products that could be attributed in most cases to another illness. Owing to the wide range of values in each lung scan diagnostic category, raised concentrations of these fibrin degradation products cannot be used without reference to the patient's clinical state as a discriminatory test for pulmonary embolism. Further evaluation of the significance of normal concentrations in excluding a diagnosis of pulmonary embolism appears to be warranted.
\end{abstract} thrombosis, such as fibrinopeptide $A$ and $\beta$ specifically and are uninfluenced by fibrinogenolysis. The assays can be performed in plasma, eliminating the artefact seen in results obtained from serum, ${ }^{8}$ and they provide a simple and accurate measurement of the derivatives of cross linked fibrin, the major fibrin form found in in vivo thrombi.

As well as indicating fibrinolysis, increased levels of cross linked fibrin degradation products are an indirect but apparently accurate marker of intravascular thrombosis. Raised concentrations occurred in all patients with clinical or occult deep vein thrombosis confirmed by venography, ${ }^{910}$ and their measurement has been proposed as a screening test for the condition. We investigated the value of the measurement in patients with suspected pulmonary embolism.

\section{Methods}

Six hundred and fourteen consecutive patients (aged 19-92 years) undergoing ventilationperfusion lung scanning because of suspected pulmonary embolism were enrolled prospectively in the study. Data collected before scanning included clinical history and examination findings, chest radiograph, electrocardiogram, arterial blood gas tensions, venogram, the full blood count, and a biochemical screen. Patients were classified as inpatients if the suspected embolism complicated another medical or surgical illness, such as myocardial infarction or the aftermath of surgery, and as outpatients if there was no other disorder requiring hospital admission.

Citrated plasma for assay of cross linked fibrin degradation products were taken immediately before scanning. Samples were assayed by both enzyme immunoassay ${ }^{11}$ (Dimertest EIA, Agen) and latex assay ${ }^{12}$ (Dimertest Latex Agen). Both assays use the monoclonal antibody DD-3B6/22 to the $\mathrm{D}$ dimer and other cross linked derivatives. The normal ranges produced by these assays are: enzyme immunoassay $0-250 \mathrm{ng} / \mathrm{ml}$; latex 0 . Acquisition of lung scans was by a modification of the method of Smart $e t a l,{ }^{13}$ with a six view technetium-99m diethyltriamine pentacetic acid (DTPA) aerosol ventilation study and a six view ${ }^{99 \mathrm{~m}} \mathrm{Tc}$ macroaggregated albumin perfusion study. A high resolution collimator was used with a large field of vision camera to obtain anterior, posterior, and both right and left anterior and posterior oblique views. All patients had a chest radiograph within 12 hours of their scans.

All scans were interpreted by a single 
Table 1 Criteria used for classification of ventilationperfusion lung scans

Definition of a defect
Small: $\quad<25 \%$ of segment
Subsegmental: $\quad 25-75 \%$ of segment
Segmental: $\quad 75-100 \%$ of segment
Whole lobe: multiple segments
Normal scan
Normal ventilation and perfusion
Scans with the following probabilities of pulmonary
embolism:
High probability
Two or more segmental or subsegmental regions of
ventilation-perfusion mismatch
Low probability
Small defects or only matching ventilation-perfusion
defects
Indeterminate probability
Single ventilation-perfusion mismatch
or
Perfusion abnormality matching radiographic change
or
Diffuse ventilation abnormalities such that there are
uncertainties about whether areas are matched or
mismatched

nuclear physician (JE-V) and classified according to Biello et al, ${ }^{14}$ with modifications by Alderson et $a l^{15}$ and Davis et $a l^{16}$ (table 1). This classification was made without knowledge of the concentration of cross linked fibrin degradation products. No patient underwent pulmonary angiography.

Reasons for exclusion from the study were: no sample for assay of cross linked fibrin degradation products (74); second or subsequent progress scans (22); incomplete ven-

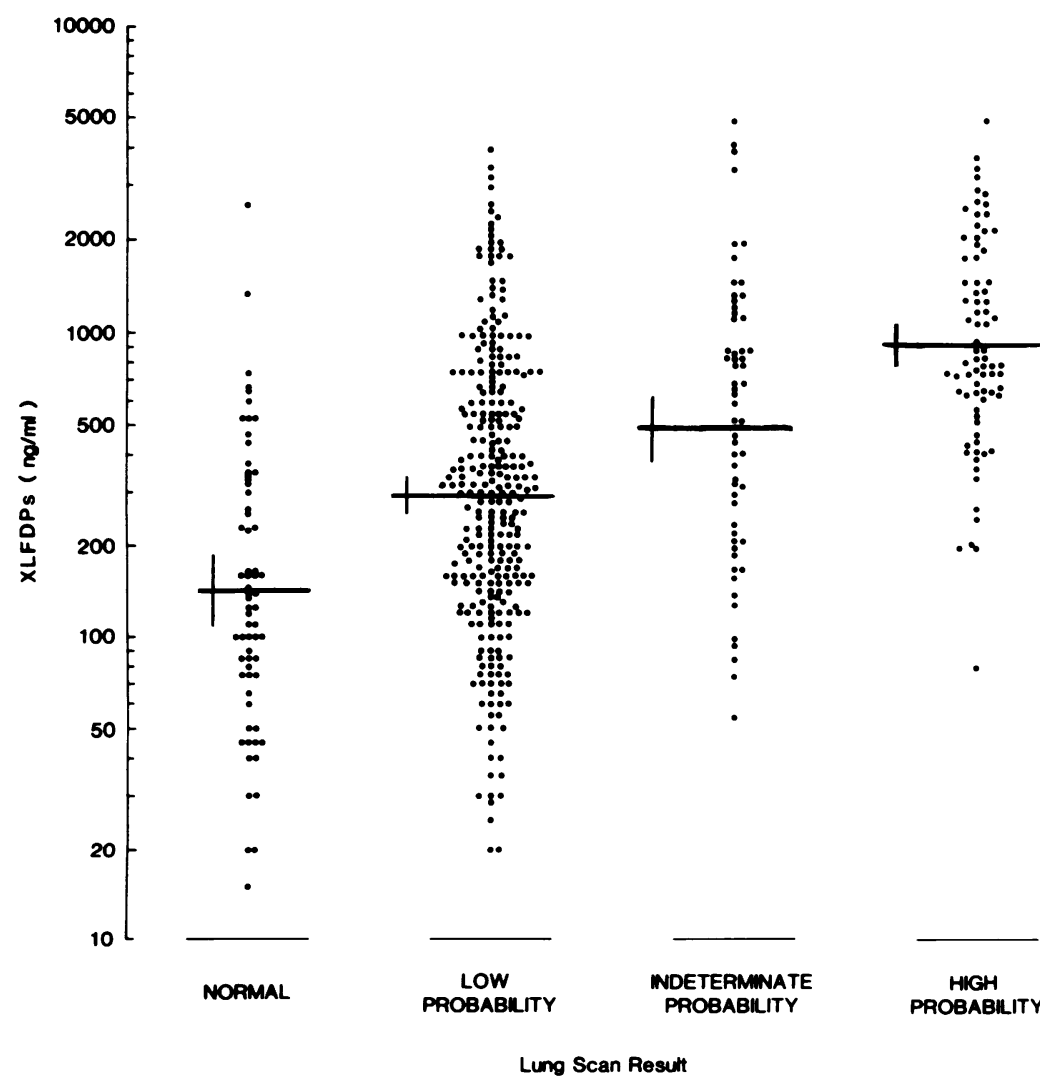

Concentrations of cross linked fibrin degradation products (XLFDPs) in patients who had ventilation-perfusion lung scans because of suspected pulmonary embolism (means with $95 \%$ confidence intervals). tilation-perfusion scan (11); ventilation-perfusion scan films not available for review (12).

Data were analysed by analysis of variance, $t$ tests, and Fisher's exact test. The distribution of the concentrations of cross linked fibrin degradation products was skewed, so all analyses were conducted on data transformed to $\log _{\mathrm{e}}$.

\section{Results}

Of the 495 scans, 66 were considered to be normal; 292 were considered to have a low, 58 an indeterminate, and 79 a high probability of pulmonary embolism. The mean concentration of cross linked fibrin degradation products increased in each lung scan diagnostic category as the probability of pulmonary embolism increased. Mean concentrations ranged from $142 \mathrm{ng} / \mathrm{ml}$ in patients with a normal scan to $952 \mathrm{ng} / \mathrm{ml}$ in patients with a high probability scan $(F=47 \cdot 0,3,491 \mathrm{df} ; \mathrm{p}$ $<0.001$ ) (figure). The mean concentration of cross linked fibrin degradation products in the group with a high probability scan was significantly higher than that of the other diagnostic groups combined $(\mathrm{F}=11 \cdot 4,1,493 \mathrm{df} ; \mathrm{p}<$ $0.001)$.

There was no difference between mean concentrations of cross linked fibrin degradation products in inpatients and in outpatients in the group as a whole, though inpatients with a normal or low probability scan had higher concentrations than outpatients in this group (inpatients $361 \mathrm{ng} / \mathrm{ml}$, outpatients $185 \mathrm{ng} / \mathrm{ml}$; $t=6.41,356 \mathrm{df}, \mathrm{p}<0.001)$.

Seventy six of 79 patients $(96 \%)$ with a lung scan with a high probability of pulmonary embolism had concentrations of cross linked fibrin degradation products greater than the normal range of $0-250 \mathrm{ng} / \mathrm{ml}$. Raised concentrations were also seen in 179 of 350 patients $\left(43^{\circ}{ }_{0}\right)$ with scans having a low or indeterminate probability of pulmonary embolism. The underlying conditions in these patients are listed in table 2 . Substantially increased concentrations could be attributed to another condition in $85 \%$ of cases, but mild increases $(250-400 \mathrm{ng} / \mathrm{ml})$ were unexplained.

In patients with a high probability lung scan the mean concentrations of cross linked fibrin degradation products in patients receiving heparin at presentation for the scan was lower $(842 \mathrm{ng} / \mathrm{ml})$ than the concentrations in patients not receiving heparin $(1088 \mathrm{ng} / \mathrm{ml})$, but the difference was not significant.

Table 2 Conditions in patients with a low or indeterminate probability of pulmonary embolism on the ventilationperfusion lung scan

\begin{tabular}{ll}
\hline & $\begin{array}{l}\text { No of } \\
\text { patients }\end{array}$ \\
\hline Recent surgery & 69 \\
Malignancy & 44 \\
Cardiac failure & 39 \\
Pneumonia & 31 \\
Orthopaedic condition & 23 \\
Deep vein thrombosis & 16 \\
Peripheral vascular disease & 11 \\
Mural thrombosis & 2 \\
\hline
\end{tabular}


Table 3 Titres of cross linked fibrin degradation products in patients having ventilation-perfusion lung scans for suspected pulmonary embolism

\begin{tabular}{lllllr}
\hline & \multicolumn{2}{l}{ Number of patients } & & \\
\cline { 2 - 6 } & & \multicolumn{2}{l}{ Scan with probability of pulmonary embolism: } \\
\cline { 2 - 6 } Latex titre & Normal scan & Low & Indeterminate & High & All scans \\
\hline 0 & 58 & 176 & 24 & 7 & 265 \\
1 & 7 & 59 & 13 & 20 & 131 \\
$>1$ & 1 & 57 & 21 & 52 & \\
\hline$\chi^{2}=121,1 \mathrm{df}, \mathrm{p}<0.001$. & & & &
\end{tabular}

The results obtained by latex assay showed changes parallel to those obtained by enzyme immunoassay (table 3). There was a highly significant difference in latex titre in each lung scan diagnostic group $\left(\chi^{2}=121,1 \mathrm{df}, \mathrm{p}<\right.$ $0 \cdot 001)$.

\section{Discussion}

This report confirms observations that cross linked fibrin degradation products are increased in patients with pulmonary embolism. ${ }^{11}{ }^{17}$ Although an embolism is an obvious source for these fibrin degradation products in plasma, disseminated intravascular coagulation is frequent and may be an invariable complication of pulmonary embolism. ${ }^{19} \mathrm{Mc}-$ $\mathrm{Kay}^{20}$ proposed that liberation of bound or sequestered thrombin from the embolus as it travels to and disintegrates in the pulmonary vascular bed is responsible for systemic activation of the coagulation system and widespread fibrin deposition. The cross linked fibrin degradation products measured in pulmonary embolism derive then from systemic fibrin and the thromboembolus. As the concentrations derived from latex assay and enzyme immunoassay are similar, only the latter will be discussed.

It is apparent that the rise in cross linked fibrin degradation products after pulmonary embolism is early and short lived. Peak concentrations occur within one hour of experimental pulmonary embolism in dogs, though concentrations were still above normal at 24 hours. ${ }^{21}$ As their half life after generation is about two hours (personal observation), these fibrin degradation products should be measured as close to the event as possible. In most of our patients lung scans were performed within 24 hours of being requested. Clinical suspicion of pulmonary embolism was high in this study $(84 \%$ of scans were not regarded as having a high probability of pulmonary embolism), but clinical suspicion would not be synchronous with the embolic event; a delay in scanning may have been responsible for normal concentrations of cross linked fibrin degradation products in the three patients with a high probability lung scan.

A further explanation for the discrepant group with normal concentrations of cross linked fibrin degradation products is that the lung scan diagnosis is incorrect. The best estimate of agreement between lung scans considered to show a high probability of pulmonary embolism and pulmonary angiograms is $90 \%$ in both prospective and retrospective series. ${ }^{22-24}$ Thus the $4 \%$ of patients in our series with normal concentrations of cross linked fibrin degradation products fall within the accepted range of possible error in the lung scan diagnosis. A further possible explanation for normal or borderline increases in cross linked fibrin degradation products in patients with a high probability of pulmonary embolism according to the scan relates to heparin treatment. Heparin inhibited the generation of fibrin degradation products after experimental pulmonary embolism in dogs, probably by inhibiting systemic fibrin formation. ${ }^{21} \mathrm{Al}-$ though the mean concentration of cross linked fibrin degradation products in patients receiving heparin at the time of scanning did not differ from that of the patients not receiving it, six of seven patients with a high probability lung scan and low concentrations of the fibrin degradation products (less than $400 \mathrm{ng} / \mathrm{ml}$ ) were being treated with heparin.

Concentrations of cross linked fibrin degradation products were raised in $43 \%$ of patients with normal, low, or indeterminate probability scans. This was anticipated and two explanations are offered. The issue of the accuracy of lung scan diagnosis has already been raised. Whereas a normal perfusion scan is generally agreed to exclude pulmonary embolism, the interpretation of an abnormal perfusion scan is less straightforward. ${ }^{22-24}$ The incidence of pulmonary embolism, as diagnosed subsequently from the pulmonary angiogram, in patients with lung scans having a low probability of pulmonary embolus is $10 \%$ and in those with indeterminate probability scans $25 \% .{ }^{22}$ In the only published prospective study the incidence of pulmonary embolism in such patients was appreciable, $25-40 \%$, depending on the lung scan diagnostic criteria. ${ }^{2324}$ This is supported by data from the recently completed PIPED study (Prospective Investigation in Pulmonary Embolism Diagnosis; $\mathrm{H}$ Salzman, personal communication). Our patients did not have pulmonary angiography as this is not used routinely to diagnose pulmonary embolism because of the risk, the cost, and the need for facilities and experience in interpretation. Even when pulmonary angiography was incorporated in a protocol, $30 \%$ of patients did not undergo the procedure, largely because of medical contraindications. ${ }^{24}$ Some of the patients in our study, however, with increased cross linked fibrin degradation products but lung scans considered to have a low or indeterminate probability of pulmonary 
embolism are likely to have had a pulmonary embolism.

Increased cross linked fibrin degradation products in patients with a negative ventilation-perfusion scan may also occur if they are derived from another source of intravascular fibrin. The assay is very sensitive to the products of lysis $(1 \mathrm{ng} / \mathrm{ml})$ and although specific for that process it is not specific for disease category. The disorders listed in table 2 are known to be complicated by intravascular fibrin deposition and its attendant lysis.

Reports ${ }^{1718}$ on the use of measurements of cross linked fibrin degradation products in the diagnosis of pulmonary embolism have produced conflicting results. Goldhaber et $a^{17}$ measured concentrations of cross linked fibrin degradation products in patients with a normal lung scan and positive pulmonary angiograms (positive diagnosis) and concluded that increased concentrations were not an accurate marker of pulmonary embolism. The quoted sensitivity $(89 \%)$ was, however, similar to the accepted sensitivity of a high probability lung scan and pulmonary angiogram. ${ }^{22}$ The high percentage of patients in their study with a normal scan and raised concentrations of cross linked fibrin degradation products without apparent cause is contary to our experience. Others have claimed high sensitivity $(100 \%)$ and specificity $(81 \%)$ and proposed a direct correspondence between concentrations of these fibrin degradation products and risk of pulmonary embolism. ${ }^{18}$

Our experience with a large study group indicates that, despite statistically different mean concentrations in the lung scan diagnostic groups, the range of values is such that cross linked fibrin degradation product concentration alone in an individual patient is insufficient to determine the risk of pulmonary embolism. The positive predictive value of the test-that is, in predicting a high probability scan-is only $26 \%$. The negative predictive value of the test is, however, high $(98 \cdot 5 \%)$.

Lung scans of low or indeterminate probability may be insufficient grounds for excluding pulmonary embolism. ${ }^{23}{ }^{24}$ Although pulmonary angiography would help in these cases, it may not be practical. Seventy one per cent of scans in this series were in these categories. Measurement of cross linked fibrin degradation products might prove a useful adjunct in this setting and deserves further study in conjunction with angiography. Normal concentrations in a promptly drawn blood sample before anticoagulation should increase confidence in a lung scan diagnosis of low probability of pulmonary embolism, and a raised concentration without other explanation in patients with a scan having a low or indeterminate probability of pulmonary embolism increases the probability of pulmonary embolism. Although concentrations of cross linked fibrin degradation products offer insights into the pathogenesis of pulmonary embolism and may yet be of clinical use, measurement of their concentration without reference to the patient's clinical state cannot be recommended as a discriminatory test for pulmonary embolism.

We gratefully acknowledge the assistance of Mrs M E Bunce, Ms J Young and Mr N Kime.

1 Yudelman IM, Nossel HL, Kaplan KL, Hirsh J. Plasma fibrinopeptide A levels in symptomatic venous thromboembolism. Blood 1978;51:1189-95.

2 Van Hulsteijn H, Briet E, Koch C, Hermans J, Bertina R. Diagnostic value of fibrinopeptide $A$ and beta-thromboglobulin in acute deep venous thrombosis and pulmonary embolism. Acta Med Scand 1982;211:323-30.

3 Farrell RJ, Duffy MJ, Duffy GJ. Serum fragment E and plasma beta-thromboglobulin in patients with acute pulmonary embolism and non-thromboembolic lung diseases. Thromb Res 1982;27:231-4.

4 Rickman FD, Handin R, Howe JP, Alpert JS, Dexter L, Dalen JE. Fibrin split products in acute pulmonary embolism. Ann Intern Med 1973;79:664-8.

5 Ruckley CV, Das PC, Leitch AG, et al. Serum fibrin/ fibrinogen degradation products associated with postoperative pulmonary embolus and venous thrombosis. $\mathrm{Br}$ Med J 1970;iv:395-8.

6 Bynum LJ, Crotty CM, Wilson JE. Diagnostic value of tests of fibrin metabolism in patients predisposed to pulmonary embolism. Arch Intern Med 1979;139:283-5.

7 Nieuwenhuizen W. Plasma assays for derivatives of fibrin and fibrinogen, based on monoclonal antibodies. Fibrinolysis 1988;2:1-5.

8 Gaffney PJ, Perry MJ. Unreliability of current serum fibrin degradation product (FDP) assay. Thromb Haemostas 1985;53:301-2.

9 Rowbotham BJ, Carroll P, Whitaker AN, et al. Measurement of crosslinked fibrin derivatives-use in the diagnosis of venous thrombosis. Thromb Haemostas the diagnosis of

10 Whitaker AN, Masci P, Rowbotham BJ, et al. Applications of plasma assays of crosslinked fibrin degradation products (XLFDP) in the diagnosis of thromboembolic disease. In: Lowe GDO, Douglas JT, Forbes CD, eds. Fibrinogen 2. Biochemistry, physiology and clinical relevance. Amsterdam: Elsevier, 1987:205-8.

11 Whitaker AN, Elms MJ, Masci PP, et al. Measurement of crosslinked fibrin derivatives in plasma: an immunoassay using monoclonal antibodies. J Clin Pathol 1984;37 882-7.

12 Elms MJ, Bunce IH, Bundesen PG, et al. Rapid detection of crosslinked degradation products in plasma using monoclonal antibody coated latex particles. Am J Clin Pathol clonal antibody

13 Smart RC, Lyons NR, Burke JJ, Wood CF. A combined procedure for $99 \mathrm{~m}$ Tc aerosol ventilation and perfusion imaging. Eur J Nucl Med 1985;11:65-8.

14 Biello DR, Mattar AG, McKnight RC, Siegel BA. Ventilation-perfusion studies in suspected pulmonary embolism. AJR 1979;133:1033-7.

15 Alderson PO, Biello DR, Sachariah KG, Siegel BA. Scintigraphic detection of pulmonary embolism in patients with obstructive pulmonary disease. Radiology 1981;138 $661-6$.

16 Davis RB, Schauwecker DS, Siddiqui AR, et al. Indeterminate lung imaging: can the number be reduced? Clin Nucl Med 1986;11:577-84.

17 Goldhaber SZ, Vaughn DE, Tumeh SS, Loscalzo J. Utility of cross-linked fibrin degradation products in the diagnosis of pulmonary embolism. Am Heart $J$ 1988;116: 505-8.

18 Bounameaux H, Slosman D, De Moerloose PL, Reber G. Diagnostic value of plasma D-dimer in suspected pulmonary embolism. Lancet 1988;ii: 628 .

19 Merskey C, Johnson AJ. Diagnosis and treatment of disseminated intravascular thrombosis. Thromb Diath seminated intravascular thromb
Haemorrh 1966:21(suppl):555-63.

20 McKay DG, Franciosi R, Zeller J. Pulmonary embolism and disseminated intravascular coagulation. Am J Cardiol 1967;20:374-80.

21 Cade J, Hirsh J, Regoeczi E. Mechanisms for elevated fibrin/ fibrinogen degradation products in acute experimental pulmonary embolism. Blood 1975;45:563-8.

22 Wellman HN. Pulmonary thromboembolism: current status report on the role of nuclear medicine. Semin Nucl Med 1986;16:231-74.

23 Hull RD, Hirsh J, Carter C, et al. Pulmonary angiography, ventilation lung scanning, and venography for clinically suspected pulmonary embolism with abnormal perfusion lung scan. Ann Intern Med 1983;98:891-9.

24 Hull RD, Hirsh J, Carter C, et al. Diagnostic value of ventilation-perfusion lung scanning in patients with suspected pulmonary embolism. Chest 1985;88:819-28. 